\title{
Uma Questão para a Educacão Inclusiva: Expor-se ou Resguardar-se?
}

\author{
A Question for Inclusive Education: \\ Be Exposed or Protect Oneself?
}

Una Cuestión para la Educación Inclusiva: ¿Exponerse o Resguardarse?

Marie Claire Sekkel, Raquel Zanelatto \& Suely de Barros Brandão

Universidade de São Paulo

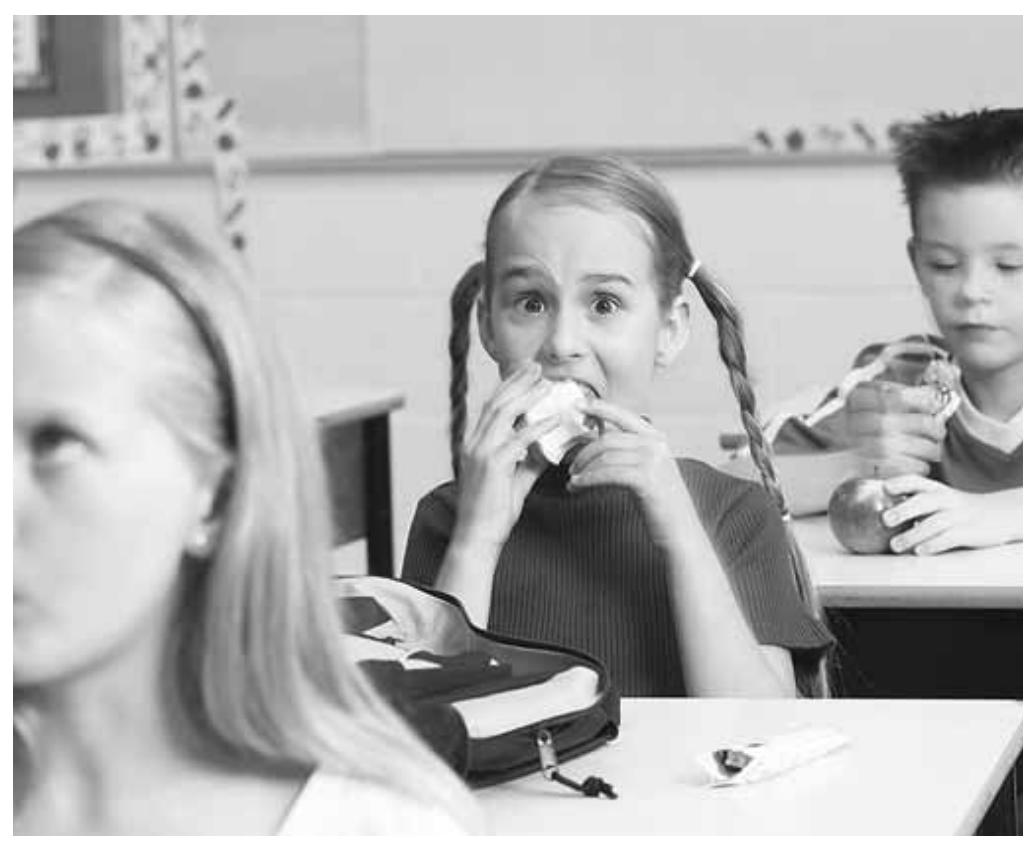


Resumo: Este artigo discute as relações entre os atores institucionais que participam de uma proposta de educação escolar inclusiva. Com essa finalidade, foram utilizados recortes dos dados coletados em uma pesquisa sobre a construção de ambientes inclusivos, realizada em uma escola municipal de educação infantil em São Paulo, no período de 2006 a 2008. Os dados foram organizados em torno da questão expor-se ou resguardar-se?, que dá visibilidade aos movimentos presentes nas relações institucionais. A pesquisa utilizou a etnografia como método de coleta de dados, e a análise foi feita com base no referencial da teoria crítica da sociedade. Os resultados apontam a presença do sentimento de ameaça, que gera a necessidade de resguardo, e também de situações de abertura à experiência no trabalho desenvolvido com as crianças, que pressupõem a necessidade de expor-se diante de si e do(s) outro(s). Segundo autores da Escola de Frankfurt, a origem desse sentimento de ameaça é social, e o medo deve tornar-se consciente para que seus efeitos destrutivos para o indivíduo e para as relações sociais possam ser evitados. A abertura à experiência, por outro lado, é necessária para a produção de uma consciência verdadeira, que é o principal objetivo da educação segundo Theodor Adorno, e deve ser considerada elemento fundamental para os processos educacionais inclusivos.

Palavras-chave: Educação inclusiva. Inclusão escolar. Deficiência. Educação Infantil.

Abstract: This article debates the relationship among the institutional actors who take part in the proposal of an inclusive education, using data collected in a survey about the construction of inclusive environments carried out in a municipal school for elementary school in São Paulo, from 2006 to 2008. The data were organized around the question exposing or protecting oneself?, which stresses the movements present in such institutional relationships. Ethnography was the data collecting method followed, and the analysis was based on the critical theory of society. The results point out both the presence of the feeling of threat, which leads to the need of protecting oneself, and situations of openness to the experience in the work developed with the children, which presupposes the need to expose oneself to oneself and to others. According to the authors of the Frankfurt School the cause of this threat is social, and the fear must become conscious in order that its destructive effects for both the individual and social relationships can be avoided. The availability to experience, on the other hand, is necessary for the production of a true consciousness, which is the main objective of education according to Theodor Adorno, and can be considered a fundamental element for the inclusive educational processes.

Keywords: Inclusive education. Scholar inclusion. Deficiency. Elementery school.

Resumen: Este artículo discute las relaciones entre los atores institucionales que participan en una propuesta de educación escolar inclusiva. Con esa finalidad, fueron utilizados recortes de los datos colectados en una pesquisa sobre la construcción de ambientes inclusivos, realizada en una escuela municipal de educación infantil en São Paulo, en el período de 2006 a 2008. Los datos fueron organizados en torno de la cuestión ¿exponerse o resguardarse?, que da visibilidad a los movimientos presentes en las relaciones institucionales. La pesquisa utilizó la etnografía como método de colecta de datos, y el análisis fue efectuado con base en el referencial de la teoría crítica de la sociedad. Los resultados apuntan la presencia del sentimiento de amenaza, que genera la necesidad de resguardo, y también de situaciones de apertura a la experiencia en el trabajo desarrollado con los niños, que presuponen la necesidad de exponerse delante de sí y del (los) otro(s). Según autores de la Escuela de Frankfurt, el origen de ese sentimiento de amenaza es social, y el medio debe tornarse consciente para que sus efectos destructivos para el individuo y para las relaciones sociales puedan ser evitados. La apertura a la experiencia, por otro lado, es necesaria para la producción de una consciencia verdadera, que es el principal objetivo de la educación según Theodor Adorno, y debe ser considerada elemento fundamental para los procesos educacionales inclusivos.

Palabras clave: Educación inclusiva. Inclusión escolar. Deficiencia. Educación infantil.

Este artigo tem como objetivo contribuir para o avanço na implementação da educação escolar inclusiva. São apresentados recortes de dados coletados em uma investigação realizada em uma escola municipal de educação infantil - EMEI - de São Paulo, cujo objetivo foi identificar os determinantes para a construção de ambientes inclusivos a partir da experiência de inclusão de crianças com deficiência. O conceito de ambiente inclusivo amplia o foco da discussão sobre a forma de inclusão de crianças com deficiência na escola regular para a forma de inserção dos professores, dos alunos, dos 
Crochík (2006) chama a atenção para o fato de que mais importante do que o ato de violência cometido na humilhação é o seu significado. pais, dos profissionais de apoio ao trabalho pedagógico (secretários administrativos, auxiliares de serviços gerais, bedeis, etc.), das equipes técnicas (diretores, orientadores educacionais, etc.) e da comunidade no processo educacional escolar (Sekkel, 2003). A análise dos dados da pesquisa evidenciou a importância dos movimentos de exporse e resguardar-se ou de ser exposto ou resguardado, na dinâmica das relações institucionais, para a construção de ambientes inclusivos. Esses movimentos dão visibilidade a elementos presentes nas relações entre os atores institucionais que são determinantes dos processos de inclusão.

A reflexão em torno da questão expor-se ou resguardar-se? referida à deficiência tem inspiração na obra de Lígia Assumpção Amaral, que retoma essa pergunta em diversos momentos do seu percurso acadêmico. $\mathrm{Na}$ introdução de Resgatando o Passado: Deficiência como Figura e Vida como Fundo (Amaral, 2003), Lígia destaca aquela que considera a maior dificuldade relacionada à deficiência: expor-se diante de si mesmo. A aceitação de si próprio é uma condição necessária à inclusão, e o primeiro movimento para alcançá-la é expor-se diante de si mesmo e, então, fazer a opção de expor-se ou de resguardar-se diante do outro.

Vale destacar que há uma diferença fundamental entre expor-se e ser exposto, bem como entre resguardar-se e ser resguardado. $\mathrm{O}$ ato de ser exposto sem estar disponível para tal, ou em um ambiente ameaçador, é uma forma de violência. Invadir a intimidade humilha, e cada sociedade prevê normas morais como forma de garantir o direito à privacidade. La Taille (2002) menciona a importância do direito ao segredo como forma de preservação da intimidade. Todas as formas de exposição que de algum modo façam incidir sobre a pessoa algum julgamento negativo que a coloque em um lugar de inferioridade são humilhantes. La
Taille distingue três categorias de humilhação: as domesticadas, que são toleráveis (por exemplo, as piadas), as ritualizadas, que são passageiras (um exemplo seria o trote), e as violentadoras, que "expressam a intenção de rebaixar pessoas ou grupos, e de mantê-los, se possível para sempre, na posição humilde que Ihes é reservada" (p. 245). O autor assinala que o tipo de humilhação violentadora está muito presente no nosso cotidiano (o pai que olha feio, o professor que humilha os alunos, o olhar da autoridade para os subalternos, o marido que bate na mulher, etc.) e comenta que há certa tolerância social com esse tipo de violência.

Crochík (2006) chama a atenção para o fato de que mais importante do que o ato de violência cometido na humilhação é o seu significado. Nesse sentido, o tapa na cara dói menos pela dor física provocada do que pelo significado que o acompanha. Ressalta também que não só as repercussões públicas são importantes e dolorosas mas também aquelas que atingem o ideal de ego, ou seja, o olhar do outro introjetado. Nesse sentido, "a humilhação é vivida como se fosse uma decepção frente aos pais, o que gera o receio de ser abandonado por eles" (p. 85). Em consequência, os sentimentos de fragilidade e de culpa poderão levar à busca de um objeto externo, que se torna alvo dessa força destrutiva, que é, em muitos casos, movida pelo preconceito. A humilhação evidencia uma situação de desigualdade.

Do mesmo modo que a exposição, o ato de resguardar alguém, impedindo o seu acesso a oportunidades de desenvolvimento, também é violento, pois retira da pessoa a prerrogativa de buscar a satisfação de seus desejos e necessidades. Resguardar pode aparecer em diferentes situações, com significados distintos: retirar da vista, manter sob proteção ou impedir o acesso às situações sociais.

A necessidade de resguardar-se, isto é, de esconder-se, de agir fora da vista do 
outro, também está associada à violência. O sentimento de ameaça leva as pessoas a procurarem se resguardar de algo que é vivenciado como perigo. Essa é uma medida de autopreservação, que deve ser respeitada. Quando se tem o cuidado de explicitar os princípios, valores e regras vigentes em um determinado ambiente institucional, isso o torna menos ameaçador, e, nesse sentido, mais inclusivo. No entanto, não se deve ter a expectativa de que a mudança de atitude seja algo simples e se processe a partir de informações. Não é a informação sobre como se deve proceder nem a fundamentação teórica para tal que faz falta.

As ações baseadas em mitos aprendidos ao longo da vida, repetidas de forma irrefletida, nos mantêm alienados e alheios ao outro, perpassados pela frieza. A tomada de consciência dos modos de pensar, sentir e agir cristalizados favorece a reflexão. A capacidade de produzir um estranhamento nos modelos habituais de pensar, sentir e agir e proceder a uma autorreflexão crítica permite uma abertura à experiência. Nesse sentido, não se trata de incentivar o amor e a compreensão entre as pessoas, mas de combater a indiferença diante do sofrimento alheio. Isso significa considerar a violência presente entre nós, e não um futuro idealizado. Como diz Adorno (1995, p. 136), "o primeiro passo seria ajudar a frieza a adquirir consciência de si própria, das razões pelas quais foi gerada".

Walter Benjamin (1993) associa essa abertura à experiência ao narrador, que "retira da própria experiência o que ele conta: sua própria experiência ou a relatada pelos outros. E incorpora as coisas narradas à experiência dos seus ouvintes" (p. 201). Esse movimento exige que o narrador se exponha, pois aquilo que conta é inseparável de sua própria experiência. "Seu dom é poder contar sua vida; sua dignidade é contá-la inteira" (p. 221, grifos do autor). Contar sua vida é, sem dúvida, expor-se, e nessa qualidade de inteireza se encontra um ponto fundamental: não se trata tão somente de rememorar o vivido. As recordações são vivas e podem propiciar a redescoberta do presente. Essa intensidade viva indica a qualidade de inteireza a que Benjamin se refere. Trata-se de um movimento sobre o qual o narrador não tem controle, mas ao qual se entrega, revelando-se a si mesmo e ao outro. É na relação com o outro que essas recordações são suscitadas.

A experiência representa a oportunidade de viver o presente, e obriga ao enfrentamento de nossas defesas e dos medos que subjazem a elas. É interessante destacar que a concepção de experiência aqui utilizada não se refere àquela presente no senso comum a que alude Benjamin (2002): "depois vem a grande 'experiência', anos de compromisso, pobreza de idéias, lassidão. Assim é a vida, dizem os adultos, eles já experimentaram isso" (p. 22). A ideia de experiência aqui empregada está intimamente associada à consciência da realidade, como aponta Adorno (1995):

\begin{abstract}
Mas aquilo que caracteriza propriamente a consciência é o pensar em relação à realidade, ao conteúdo - a relação entre as formas e estruturas de pensamento do sujeito e aquilo que este não é. Este sentido mais profundo de consciência ou faculdade de pensar não é apenas o desenvolvimento lógico formal, mas corresponde literalmente à capacidade de fazer experiências. (p. 151)
\end{abstract}

Os estereótipos, fornecidos pela cultura, impedem a experiência com aquele que querem representar e servem à concretização de atitudes preconceituosas. O preconceito guarda sempre um desconhecimento em relação àquele que é o seu alvo, e impede a experiência com este (Amaral, 1998; Crochík, 2006). Abrir mão das formas enrijecidas de relacionamento com o outro é um processo que tem início com a tomada de consciência sobre esse modo de agir e 
exige o enfrentamento dos sentimentos a ele subjacentes e a reflexão sobre as nossas crenças e valores, tomando como ponto de partida a experiência. Esse entendimento nos leva a pensar que qualquer profissional da educação pode agir em contradição com os princípios e valores assumidos coletivamente na escola e não ter consciência disso. Se tal contradição puder ser apontada por outro (algum colega de trabalho) sem ser tomada como falha, poderá converter-se em uma oportunidade de crescimento. Por outro lado, se tal ação for tomada (apenas) como um erro pessoal, isso poderá levar à fragilização diante do olhar do outro, reafirmando a necessidade de resguardar-se.

A ameaça produz formas de exclusão muitas vezes difíceis de serem identificadas, que levam a evitar ou a agir defensivamente em situações nas quais as nossas fragilidades apareçam. As ameaças têm origem na cultura, gerando nos indivíduos a necessidade de defesa. O preconceito é uma defesa contra esse sentimento de ameaça. E é por ser defesa psicológica contra ameaças reais ou imaginárias que a atitude preconceituosa resiste à mudança e à abertura para a experiência, constituindo barreira atitudinal difícil de ser superada em todos os âmbitos em que se manifeste (Amaral, 1995, 1998; Crochík, 2006).

A educação escolar inclusiva deve ter como desafio a melhoria da qualidade no que diz respeito aos recursos e estratégias necessários à aprendizagem bem como às relações que se dão no universo escolar. A valorização da dúvida, a expressão de sentimentos e a troca de experiências são elementos que contribuem para a melhoria da aprendizagem e das relações (Adorno, 1995; Ainscow, 1997; Crochík, 2006). Pode-se considerar, portanto, que os processos inclusivos podem se fortalecer com a criação de condições atrativas ao expor-se e uma cultura de respeito ao resguardar-se, considerando sempre os limites da relação com o outro e cuidando para que os sujeitos participem das decisões institucionais que lhes dizem respeito.

A pesquisa a que se referem os dados relatados a seguir foi desenvolvida em uma escola municipal de educação infantil (EMEI), localizada na cidade de São Paulo, tendo em vista, como já foi dito, identificar os determinantes para a construção de ambientes inclusivos. Optou-se pela abordagem etnográfica por considerar que ela permite conhecer como se dão as relações entre os diversos atores que interagem no cotidiano da escola, possibilitando uma visão abrangente e significativa das relações institucionais. A coleta de dados foi realizada durante os anos 2006 e 2007, e constou de três etapas: 1) oito sessões de observação (com duração de duas horas cada) nos grupos de crianças de quatro, cinco e seis anos (Estágio I, II e III); 2) levantamento da documentação pedagógica e 3) entrevistas com as três professoras das salas observadas, com dois profissionais de apoio ao trabalho pedagógico, com a coordenadora e com pequenos grupos de crianças de cada Estágio. Para a análise dos dados, utilizou-se como referencial teórico a teoria crítica da sociedade.

No presente artigo, não serão apresentados todos os dados coletados e as análises a eles referentes, mas apenas os conteúdos das entrevistas e observações a partir dos quais se pode perceber o movimento de expor-se ou de resguardar-se, que possibilitam refletir e tecer algumas considerações a respeito da proposta de educação inclusiva. Os dados apresentados a seguir referem-se às observações e entrevistas realizadas com as professoras Monika, Gertrudes e Sandra, a coordenadora Bia e os profissionais de apoio Geraldo e Patrícia.

Perguntada sobre as dificuldades no trabalho, Monika afirma que a escola é bem equipada e 
tem muitos recursos. Disse não ter dificuldades no desenvolvimento do seu trabalho, e atribui isso à experiência: "Eu não tenho muita dificuldade, não. Deve ser a experiência, aqui e lá. Dá para ir levando numa boa. Acho que quem está iniciando sente dificuldade, assim como eu senti. Mas agora, não".

As observações realizadas evidenciaram o distanciamento de Monika, que se manteve a maior parte do tempo voltada para outros interesses enquanto as crianças brincavam no parque, supervisionando-as à distância e buscando situações em que pudesse conversar com outros funcionários ou mesmo com as pesquisadoras sobre assuntos alheios ao trabalho educacional. Algumas atividades propostas se repetiam em dias consecutivos, sugerindo a falta de investimento no planejamento do trabalho. O julgamento prévio de que um profissional experiente deve saber tudo e não sente mais dificuldade em seu trabalho pode ter como consequência o medo de expor suas dúvidas e perder a admiração dos colegas, o que poderia levar a evitar novos desafios, a fim de resguardar-se. A suposta expectativa dos outros com relação ao profissional mais experiente pode se converter em ameaça que, por sua vez, funcionaria de modo a impedir o envolvimento e o sentimento de realização no trabalho. Nas falas da professora, a expectativa pela aposentadoria é um tema em evidência, que aparece repetidas vezes nas conversas.

Monika comenta na entrevista que o planejamento das atividades é feito pela coordenadora. No entanto, em contradição com sua fala, a coordenadora pedagógica coloca que os planejamentos são feitos em grupo, afirmando que "o trabalho é diretamente ligado à professora. Eu acompanho o planejamento, a gente faz o plano anual, o plano bimestral, e as avaliações acontecem semestralmente. A gente também elabora junto". Cabe indagar como esse desencontro permanece ao longo do tempo, sem que haja a tomada de consciência do mesmo. Se cada um dos atores pode dizer do seu trabalho de modo a justificar suas ações sem que essas falas sejam em algum momento confrontadas, supõe-se que haja interesse das partes envolvidas em manter a situação como está. Esse desencontro pode ser uma forma de resguardar-se do enfrentamento.

No caso de Gertrudes, outra professora, chama a atenção nas observações a frequência e a intensidade com que humilha publicamente as crianças, como, por exemplo, ao criticar com violência diante da classe as crianças que tinham dificuldades em realizar as atividades propostas ou cujos pais não haviam enviado para a escola determinado material.

Muitas crianças tinham dificuldades em executar a atividade, e a professora passava de mesa em mesa criticando os trabalhos: "Isso não é bolinha, nem aqui nem na China. Trata de fazer direito... Olha o seu! Está horroroso!... É assim, seu tonto!" Ela achou o caderno de uma criança e o entregou a ela, em seguida, mostrou-me uma sacola dizendo em voz alta: "Um caderno, e duas revistas. A mãe só mandou isto!" Virou-se e continuou mexendo no armário. Valéria foi até ela e queixou-se de que estava sem lápis. Ela respondeu: "Paciência! Se a mãe não manda, fica sem lápis!"

Outra situação observada foi a de José Henrique, que, por manifestar alergia alimentar com intensa descamação cutânea, não podia compartilhar o lanche oferecido pela escola. Baseada nessa justificativa, Gertrudes orienta-o a comer sozinho na copa, como forma de resguardá-lo, e aos colegas, do contato com os diferentes lanches oferecidos a cada um. É importante notar que Gertrudes não perguntou a José Henrique e aos colegas qual seria a proposta mais adequada nem manifestou atenção com o bem-estar do menino ao longo das observações. Quando 
questionada pela pesquisadora, disse acreditar que ele assim o preferisse. A alergia alimentar levou à exclusão de José Henrique do grupo, diariamente, durante os momentos de refeição, mantendo-o resguardado. Nesse caso, resguardar parece significar a eliminação do problema, uma forma de exclusão que se faz acompanhar da crença no cuidado e respeito às necessidades da criança. $\mathrm{O}$ cuidado e o respeito não poderiam, no entanto, prescindir da aproximação e do diálogo com José Henrique, que tem o direito de expressar seus sentimentos e de participar dessa decisão.

Gertrudes julga que não deve expor suas queixas à coordenação, pois não adiantaria, já que parte do pressuposto de que não seria ouvida. Não procura a coordenadora, segundo conta na entrevista, porque supõe que seja esta quem deveria vir ao seu encontro, o que aguarda com resignação. Percebe-se na fala de Gertrudes em relação à coordenadora e a José Henrique a presença de suposições que se antecipam e impedem a experiência com o outro. Pode-se supor que haja nesse modo de agir uma construção defensiva, que a mantém resguardada de ameaças presentes no ambiente institucional.

Gertrudes e Monika encontram-se isoladas, constituindo um grupo fechado nelas mesmas e nas crianças de suas turmas. Não há perguntas, não há trocas, não há investimento no conhecimento, e a violência - quer como indiferença, quer como humilhação - está presente nas suas relações com as crianças, o que se evidencia nas observações.

Já a professora Sandra conta na entrevista suas dificuldades e como busca ajuda para resolver algumas situações. Sobre uma de suas primeiras experiências profissionais, afirma que o maior auxílio em sua prática veio de outras professoras:
Tinha minha tia, ela sempre estava me ajudando, aquela coisa de insegurança sabe, ainda, qualquer coisa que eu precisava de ajuda, eu corria nela: 'me ajuda, o que é que eu faço?' Teve uma outra professora também, muito legal, me ajudou bastante, sempre me dava uns toques... sempre ajudava mesmo. Ficava meio desesperada e corria na sala delas.

É Sandra também quem dá mostra de abertura à experiência no trabalho com Fabiana, criança que apresenta uma deficiência física. Critica a professora responsável por Fabiana no ano anterior, que deixou de investir e planejar atividades visando ao aprendizado da menina, por acreditar que ela estaria ali "só mesmo para o social, para ficar junto com as outras crianças". Sandra mostra indignação com essa postura, e, tomando por base sua experiência, destaca a capacidade de articulação verbal de Fabiana como indicador de seu potencial para a aprendizagem. Relata que inicialmente ficou muito assustada com a presença de uma criança com deficiência em sua turma: "Será que eu vou saber trabalhar? Será que eu vou saber lidar com o problema dela?"

Sandra diz ter pesquisado em diversas fontes ao seu alcance, sem conseguir esclarecer, no entanto, suas dúvidas. Então decide: "eu vou trabalhar com a Fabiana assim como eu vou trabalhar com qualquer criança", e relata que, com o passar do ano letivo, começou a tratar Fabiana:

como todas as outras crianças: dando bronca quando precisava dar bronca, colocando de castigo quando ela ficava de malcriação ou se recusava a fazer alguma atividade. Eu fui percebendo, e ela também foi percebendo, que ela era igual e que tinha que fazer aquilo que as outras crianças faziam. Eu sei que foi chegando uma época em que ela pedia para mim eu quero fazer.

Ao perceber que Fabiana vem acompanhando o trabalho com a turma, Sandra sentese gratificada. Vemos nesse movimento 
a abertura à experiência com Fabiana, deixando de lado os julgamentos prévios, mantendo a atenção nas manifestações da criança e pensando suas intervenções a partir delas. Sandra compartilha suas dificuldades, expondo-se diante do olhar do outro a quem pede ajuda. Isso a diferencia das outras professoras entrevistadas.

Essa abertura à experiência pode ser percebida também na entrevista com os profissionais de apoio ao trabalho pedagógico, Geraldo e Patrícia - ela, merendeira, e ele, bedel. Nas observações, é possível perceber o envolvimento de Geraldo com as crianças, o que também aparece na entrevista: "você sente gratificação pela desenvoltura deles", "pelo resultado que a gente colhe... cada vez você fica mais envolvido com a criança". O envolvimento, cujo sentido está relacionado a ter a atenção atraída pelo outro, parece ser um elemento significativo na abertura à experiência.

Geraldo mostra-se bastante criativo e aberto para experimentar novas possibilidades no trabalho com as crianças, como, por exemplo, quando consegue adaptar o balanço do parque para Beatriz, uma menina com uma deficiência nas pernas que a impedia de utilizar o balanço da maneira convencional. No entanto, percebe-se que ele atua de forma isolada dentro da escola. Quando questionado pelas crianças sobre por que uma menina que não tinha uma das pernas não andava, Geraldo conta na entrevista que "falava pra eles: 'Não, a perninha dela é assim porque ela está fazendo um tratamento, ela vai ficar como vocês, vai andar como vocês' $E$ aí eles esqueciam também". Essa fala evidencia a dificuldade de Geraldo na aceitação e no trato com as crianças em relação à deficiência, dificuldade essa que é descrita por Amaral (1998): se reconhecer a diferença significativa do outro (ou nossa rejeição a ela) nos causa profundo mal-estar, tensão e ansiedade, uma das possibilidades é o acionamento do mecanismo de defesa da negação, o qual pode revestir-se de algumas roupagens específicas: compensação, simulação e atenuação. (p. 20)

Na fala de Geraldo, percebe-se a negação da deficiência, que é tratada como uma doença que tem cura na busca de fugir à questão pelo esquecimento. Embora os profissionais de apoio interajam diariamente com as crianças, não há o reconhecimento e o suporte institucional que dê subsídios para essas ações.

Patrícia, por sua vez, reconhece o trabalho educativo que é desenvolvido pelos profissionais de apoio e acredita que seria interessante que todos que trabalham na escola tivessem conhecimentos sobre desenvolvimento infantil, para saber respeitar as fases do desenvolvimento sem cobrar das crianças algo que não sejam capazes de compreender em determinada idade.

A instituição mantém Geraldo e Patrícia em uma situação de isolamento, na medida em que não há espaço previsto para que eles possam expor suas questões e seus feitos, e não legitima o trabalho educativo que eles desenvolvem. Não podem expor-se. Essa é uma forma de exclusão.

Com relação à coordenadora $\mathrm{Bia}$, as observações realizadas contrastam com aquilo que é relatado na entrevista e com a fala das professoras em alguns pontos. Bia entende que o seu trabalho é diretamente ligado aos professores: "Eu acompanho todos os horários de estudo. Tem quase todos os dias". "Às vezes eu passo o dia todo na sala dos professores, eu nem venho para a minha sala. Principalmente terça, quarta e quinta, em que se concentra o coletivo". As 
É conhecido na Psicologia o mecanismo de defesa mediante o qual o preconceituoso projeta no outro (em geral aquele que é socialmente considerado inferior ou mais frágil) aquelas características que não pode reconhecer em si mesmo (Crochík, 2006) professoras entrevistadas não reconhecem essa proximidade, tampouco encontramos registros significativos do trabalho coletivo nas atas das reuniões. Com relação aos desafios da educação inclusiva, Bia evidencia um entendimento que se restringe às crianças cujas necessidades especiais são amplamente reconhecidas e limita-se a encaminhar os casos para instâncias externas à escola, dando a entender que todo o saber necessário às ações inclusivas vem de profissionais de outras áreas: "As crianças que têm dificuldade de aprendizagem, algum problema mais sério, também faço o encaminhamento, ou para psicólogo, ou neurologista... Eu faço esta parte de encaminhamento". "A parte de inclusão é só mais uma entre as várias funções que eu exerço. $O$ forte mesmo é o trabalho pedagógico. A inclusão aparece e eu vou dando os encaminhamentos necessários". Bia mostra um entendimento dicotomizado entre o trabalho pedagógico e a inclusão, como se a ação inclusiva fosse de natureza diferente da ação pedagógica.

Uma das características mais marcantes nas observações e nas entrevistas realizadas é a preocupação presente nos vários atores institucionais em agir de acordo com expectativas e orientações externas (às crianças, aos grupos e à própria escola). Monika, por exemplo, revela a expectativa que a escola tem com relação à produção das crianças e trabalha com meta fixa, independentemente das características do grupo.

A exposição dos trabalhos para as famílias deve corresponder a um padrão que leva as professoras a interferirem nas produções das crianças, adequando-as ao esperado. Gertrudes, ao dizer frases como "isso não é bolinha nem aqui nem na China" para uma criança que fazia as bolinhas de papel crepon da atividade proposta por ela, explicita a concepção de um modelo a ser atingido. Busca-se um resultado no qual o que importa é a aparência, porque é feito para ser exposto, atendendo a expectativas externas, que regulam o processo educacional. Quando as professoras intervêm diretamente no trabalho das crianças, pode-se supor que elas estão se resguardando do julgamento de outros: as produções devem aparentar o padrão esperado para que elas próprias não se sintam ameaçadas de serem julgadas más professoras. Isso evidencia que, já na educação infantil, as produções das crianças deixam de ser representações ligadas ao processo de construção e expressão, que lhes conferiria sentido e nas quais elas poderiam se expressar, e passam à categoria de produtos orientados por motivações externas.

A escassez de documentação pedagógica e de memória da instituição, evidenciada no levantamento de registros institucionais, pode ser entendida como reflexo desse corpo sem alma que resulta do modo de fazer descrito. Talvez se os processos tivessem um significado importante para seus atores, a necessidade de construção da memória far-se-ia sentir, como fruto do próprio envolvimento.

\section{Considerações finais}

A educação inclusiva pode ser entendida também como educação para as diferenças, isto é, para a aceitação do diferente, do outro, o que pressupõe a consciência e a aceitação de si mesmo. É conhecido na Psicologia o mecanismo de defesa mediante o qual o preconceituoso projeta no outro (em geral aquele que é socialmente considerado inferior ou mais frágil) aquelas características que não pode reconhecer em si mesmo (Crochík, 2006). Expor-se diante de si mesmo é condição para a abertura à experiência. $\mathrm{Na}$ sociedade atual, no entanto, há uma intensa pressão adaptativa que impede a experiência e a reflexão sobre a realidade.

Para Horkheimer e Adorno (1985), a 
cultura, instalada de forma conservadora, serve à justificação e ao aperfeiçoamento do existente. A subjetividade imposta socialmente busca a adesão aos modelos socialmente valorizados, como forma de sobrevivência. O mundo está dado, e só cabe a cada um a busca do sucesso adaptativo. Essa forma de subjetivação socialmente imposta pelo modo de produção capitalista, e que determina a vida em todos os planos, mesmo para além da esfera da produção, foi denominada semiformação pelos autores da Escola de Frankfurt (Maar, 2003). A semiformação não é algo restrito ao âmbito pedagógico; trata-se de uma produção social que deve ser entendida em uma dimensão que abrange a sociedade como um todo e que, como adesão ao existente, impede a experiência e a diferenciação individual, necessárias à educação inclusiva.

As escolas, como instituições sociais, reproduzem no dia a dia as contradições presentes no ambiente social. Não causa estranhamento encontrar na escola observada a marca do isolamento e da fragmentação tão características da sociedade competitiva atual. O medo domina as relações, e o sentimento de ameaça está presente para todos, pois ele tem origem social. Isso exige que nos resguardemos e que muitas vezes passemos a representar papéis com os quais não temos identificação. É difícil se expor na atualidade, e muitas vezes escondemo-nos de nós mesmos.

A pesquisa nessa EMEI permitiu constelar dados de observação, de registro e de entrevistas, de modo a alcançar uma compreensão do ambiente institucional. Há muito de previsível nesse conjunto, mas essa constelação delimitada a partir de situações concretas permite tecer algumas considerações que não teriam significado como possíveis especulações.
Uma primeira consideração diz respeito ao sentimento de ameaça, que gera medo nas relações. Como enfatiza Adorno (1995), a angústia que sentimos deve se tornar consciente e devemos nos permitir sentir o medo que a realidade atual suscita. É provável que esse medo não esteja consciente para muitos profissionais da escola, mas ele pode ser inferido a partir dos dados colhidos e deve ser trazido à consciência se quisermos evitar seus efeitos deletérios sobre as relações. É impossível que a educação seja verdadeiramente inclusiva enquanto o medo atuar de forma a obrigar as pessoas a se resguardarem com uma intensidade tal que impeça a expressão de suas necessidades e o reconhecimento de seus feitos.

Nesse ponto, cabe uma segunda consideração sobre a importância de os profissionais da escola se exporem diante de si mesmos e de seus pares. A intencionalidade desse movimento e a forma que ele poderá assumir podem ser avaliadas no âmbito do projeto pedagógico da escola. Não são novos cursos que vão ter o poder de alterar o estado de isolamento a que leva a necessidade de resguardar-se: é o lugar da experiência que precisa ser incentivado. Vale destacar que não se entende com isso que o investimento em cursos para os professores e demais profissionais da escola deva ser desprezado, mas que só esse preparo não é suficiente para promover uma educação humana.

Com base no que foi discutido anteriormente, o compartilhamento de experiências só se fará se houver acolhimento e um olhar atento voltado para o ambiente interno à escola. O que se evidencia a partir dos dados é a valorização de orientações de profissionais externos à instituição e de regras e de exigências de outras instâncias e órgãos governamentais reguladores, enquanto o que é dito no ambiente interno não pode ser ouvido, e então não é explicitado, ou é negado. Fabiana, por exemplo, é deficiente, 
e tem necessidades especiais amplamente reconhecidas, mas a necessidade especial de José Henrique não é reconhecida. Assim, o que parece necessário nesse momento é produzir o deslocamento dessa atenção voltada para fora (como guarda defensiva) e voltá-la para dentro. Nesse movimento, é importante que se produzam trocas, diálogos entre os pares sobre ideias e sentimentos relacionados ao trabalho desenvolvido, que promovam o reconhecimento de si e do outro.

Uma terceira consideração se refere ao importante papel que os coordenadores e diretores têm diante do desafio de olhar para dentro da instituição. Eles ocupam funções centrais, investidas do poder hierárquico e com acesso às instâncias superiores externas. Vimos como as expectativas externas atuam de forma decisiva no modo de pensar e agir dos professores e da coordenação, e como isso repercute na educação das crianças. $\mathrm{O}$ ambiente institucional suficientemente seguro - e, nesse sentido, resguardado - é um fator importante para permitir e atrair o envolvimento. A atenção voltada para o interior da escola convidará ao reconhecimento de potencialidades atualmente presentes, mas negadas. Podemos supor que haja necessidade de a instituição se resguardar e manter o olhar voltado para as necessidades internas, até que suas produções alcancem suficiente desenvolvimento, que poderá trazer o desejo de compartilhamento com o universo externo, buscando oportunidades de expor-se por meio de relatos, celebrações, publicações, etc.

A participação do psicólogo nesse processo pode ser de grande ajuda, não a do psicólogo clínico para o qual são encaminhados os casos que não se consegue resolver, e que atua fora do ambiente escolar. Destacamos aqui a importância do psicólogo escolar, que atue como interlocutor interno à escola, que experiencie as relações institucionais e contribua para a construção de um ambiente inclusivo, em que os atores que participam do processo educacional possam se expor.

As considerações apontadas acima nos levam a pensar que, para a escola se tornar um ambiente inclusivo, é necessário identificar e procurar reduzir os fatores que provocam o sentimento de ameaça e, ao mesmo tempo, incentivar o diálogo entre os pares e a construção da memória institucional, de modo a fortalecer o sentimento de pertencimento e o de autoria. 
Adorno, T. W. (1995). Educação e emancipação. Rio de Janeiro: Paz e Terra.

Ainscow, M. (1997). Educação para todos: torná-la uma realidade. In M. Ainscow, G. Porter \& M. Wang (Eds.), Caminhos para as escolas inclusivas (pp. 11-32). Lisboa: Instituto de Inovação Educacional.

Amaral, L. A. (1995). Conhecendo a deficiência (em companhia de Hércules). São Paulo: Robe.

Amaral, L. A. (1998). Sobre crocodilos e avestruzes: falando de diferenças físicas, preconceitos e sua superação. In J. G. Aquino, Diferenças e preconceitos na escola (pp. 11-30). São Paulo: Summus.

Amaral, L. A. (2003). Resgatando o passado: deficiência como figura e vida como fundo. São Paulo: Casa do Psicólogo.

Benjamin, W. (2002). Reflexões sobre a criança, o brinquedo e a educação. São Paulo: Editora 34.
Benjamin, W. (1993). O narrador. In W. Benjamin, Obras escolhidas: magia e técnica, arte e política (6a ed., Vol. 1). São Paulo: Brasiliense.

Crochík, J. L. (2006). Preconceito, indivíduo e cultura. São Paulo: Casa do Psicólogo.

Horkheimer, M., \& Adorno, T. W. (1985). Dialética do esclarecimento. Rio de Janeiro: Jorge Zahar.

La Taille, Y. (2002). Vergonha, a ferida moral. Petrópolis, RJ: Vozes.

Maar, W. L. (2003, agosto). Adorno, semiformação e educação. Educação \& Sociedade, 24(83), 459-476.

Sekkel, M. C. (2003). A construção de um ambiente inclusivo na educação infantil: relato e reflexão sobre uma experiência. Tese de Doutorado, Instituto de Psicologia, Universidade de São Paulo, São Paulo. 